\title{
Decidualized endometriosis causing inversion of the appendix, massive hemorrhage and fetal death
}

\author{
ANTHONy M Magliocco, MD, ROBERT MULloy, MD, ROY M PRESHAW, MD, FRCPC, \\ JAMES K KELLY, MB, FRCPath, FRCPC
}

\begin{abstract}
am Magliocco, RT Mulloy, RM Preshaw, JK Kelly. Decidualized endometriosis causing inversion of the appendix, massive hemorrhage and fetal death. Can J Gastroenterol 1991;5(1):18-20. An extraordinary case of inversion of the appendix due to decidualized endometriosis is reported. A 35-year-old woman presented at 37 weeks of pregnancy with acute massive rectal hemorrhage and fetal death. A limited right hemicolectomy was performed. The cecum contained an inverted appendix with an ulcerated tip. Histologically there was decidualized endometriosis in the ulcer bed and in all layers of the appendiceal wall.
\end{abstract}

Key Words: Appendix, Decidua, Endometriosis, Hemorrhage, Intussusception, Inversion, Pregnancy

\section{Endomédriose déciduale de l'appendice responsable d'une} inversion appendiculaire, d'une hémorragie massive et de mort foetale

RESUME: On rapporte le cas extraordinaire d'une inversion appendiculaire due à une endomédriose déciduale. La patiente âgée de 35 ans et enceinte de 37 semaines s'est présentée avec une rectorragie massive aiguë et la mort foetale a été constatée. Une hémicolectomie droite limitée a été effectuée. Le caecum contenait un appendice inverti à l'extrémité ulcérée. Histologiquement, on a relevé la présence d'endométriose dans la niche ulcéreuse et dans toutes les couches de la paroi appendiculaire.

Departments of Pathology and Surgery, Foothills Hospital and the University of Calgary, Calgary, Alberta

Correspondence and reprints: Dr J Kelly, Department of Pathology, Foothills Hospital, 1403

29 Street NW, Calgary, Alberta T2N 2T9

Received for publication April 24, 1990. Accepted September 5, 1990
Drimary apPendiceal intussus. ception is a rare pathological en. tity, occurring in less than $0.01 \%$ of all appendiceal resections, according to a survey of over 71,000 cases by Collins (1). The presence of endometriosis as a complicating or instigating factor in such cases is even rarer, with fewer than 20 cases described to date in the literature (2). The clinical picture of such cases is diverse, with symptoms varying from none to severe abdominal pain and gastrointestinal hemorrhage (3-5).

The authors report a case of appendiceal intussusception with endo. metriosis in a pregnant woman at 37 weeks gestation resulting in life threatening gastrointestinal hemorrhage and fetal death.

\section{CASE PRESENTATION}

A 35-year-old woman at 37 weeks gestation presented to hospital with a $24 \mathrm{~h}$ history of postural dizziness and passing bright red blood per rectum. There was associated mild right lower quadrant abdominal pain. The preg. 


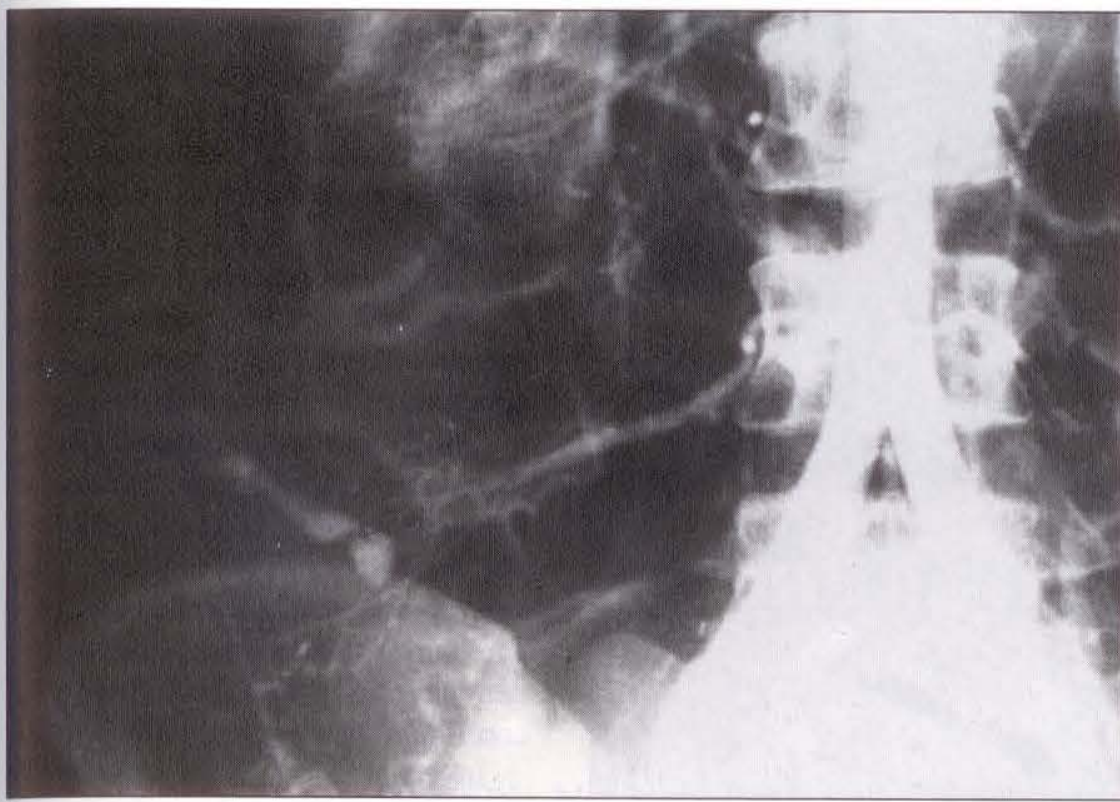

Figure 1) Mesenteric artery angiogram demonstrates tortuous vessels in the region of the cecum and extravasated dye indicating intestinal hemorrhage within the ascending colon

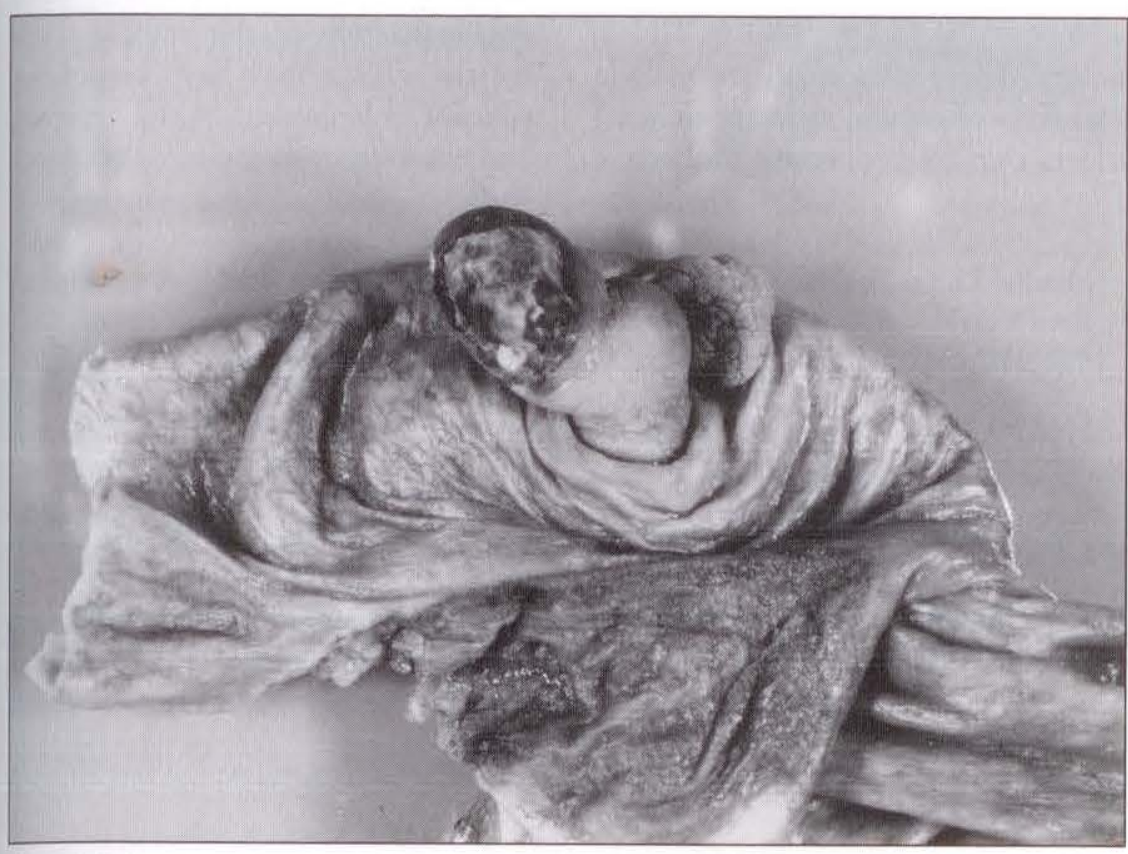

Figure 2) Gross appearance of the inverted appendix as it protruded into the cecum. The appendiceal tip shows acute ulceration with a fibrinopurulent exudate capping an area of recent hemorrhage. The sessile polyp at the base of the appendix proved to be a hyperplastic polyp and was an incidental finding

nancy to this point had been otherwise unremarkable, and before it the patient had not had the cyclic symptomatology attributable to endometriosis.

On examination, the patient was pale with tachycardia and slight diffuse abdominal tenderness. Fetal heart sounds were inaudible. Rectal examination revealed bright red blood on the glove but no rectal abnormality. Hemoglobin was reduced to $70 \mathrm{~g} / \mathrm{L}$ and clotting parameters were normal.

Upper gastrointestinal endoscopy was normal, and sigmoidoscopy revealed a colonic mucosa obscured by blood. A tagged red blood cell study failed to reveal any bleeding sites. Ultrasound examination confirmed fetal death. Once the patient was stabilized hemodynamically with fluid and blood transfusions, labour was induced. A short time after delivery, profuse rectal bleeding recurred. Immediate mesenteric angiography showed a bleeding source in a plexus of tortuous vessels in the ileocecal area (Figure 1).

At laparotomy, distended veins were noted at the termination of the anterior tenia coli. The appendix was not seen; however, a $2 \mathrm{~cm}$ diameter mass was palpated within the cecum. The other abdominal organs were entirely unremarkable; specifically, there were no other sites of venous tortuosity or endometriosis noted. A right hemicolectomy was performed because of the possibility of a cecal tumour. The patient's postoperative course was unremarkable.

\section{PATHOLOGICAL FINDINGS}

The gross specimen consisted of a $10 \mathrm{~cm}$ length of cecum with an attached $3 \mathrm{~cm}$ length of terminal ileum. The appendix was discovered to be completely intussuscepted and ulcerated at its tip (Figure 2). There was a $1.2 \mathrm{~cm}$ diameter sessile polyp located in the cecum $1 \mathrm{~cm}$ from the base of the inverted appendix, but this appeared to be coincidental.

Histology of the specimen showed ulceration and necrosis of the tip of the appendix with endometriosis in the ulcer base and in the adjacent mucosa (Figure 2). The wall of the entire length of the appendix showed submucosal, intramural and serosal endometriosis with decidualized stroma. The endometriotic tissue expanded the submucosa.

Examination of the placenta showed meconium staining and focal infarction. Fetal autopsy was not obtained.

\section{DISCUSSION}

There has been much speculation as to the cause of inversion of the appendix. Most cases are associated with chronic inflammation (6), but it is not clear whether inflammation is a primary or secondary phenomenon. Other associations include mucoceles, carcinoid tumours, polyps, foreign bodies and endometriosis (7). Anatomic or functional abnormalities 


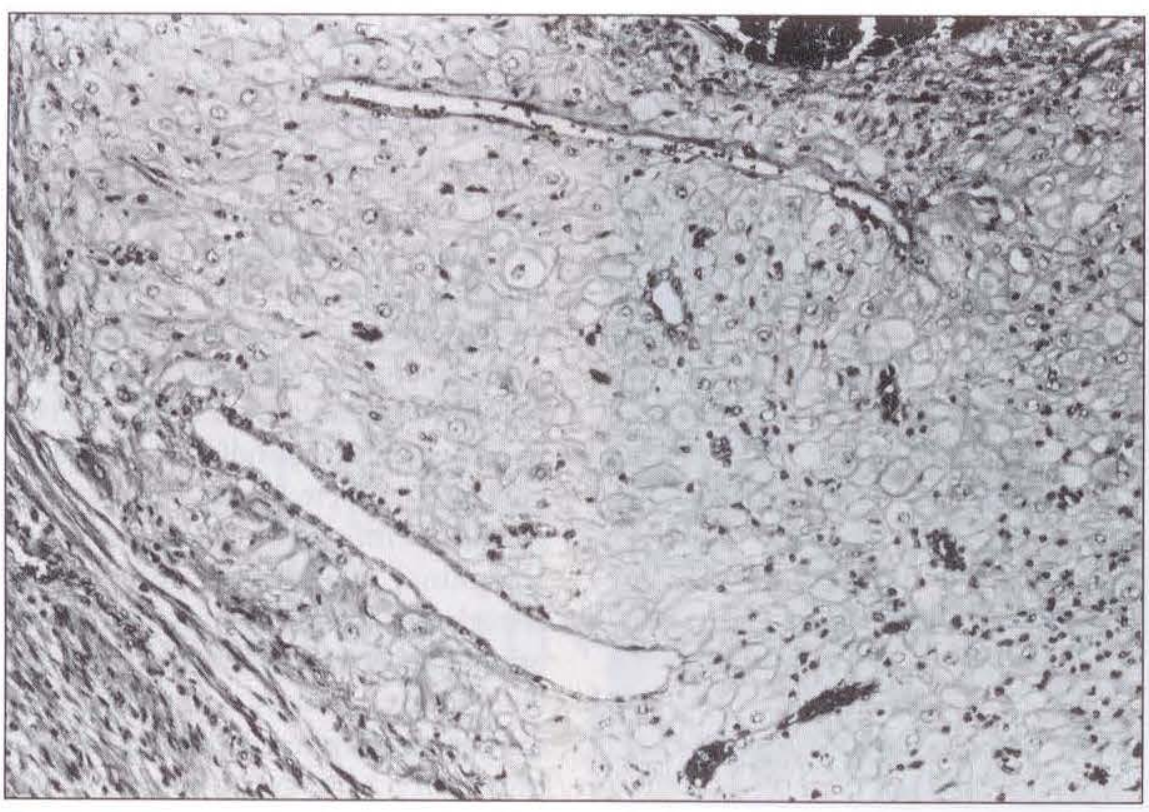

Figure 3) Microscopy of the submucosa of the appendix demonstrates decidualized endometriosis. The glands are narrow and lined with attenuated epithelium. The decidualized stromal cells are greatly enlarged with an epithelioid appearance and abundant eosinophilic cytoplasm (hematoxylin and eosin x180)

may also increase the susceptibility of a given appendix to intussusception when exposed to appropriate causative

\section{REFERENCES}

1. Collins D. 71,000 human appendix specimens. Am J Proctol 1963;14:365-81.

2. Collins D. Endometriosis of the vermiform appendix; review of the literature with addition of nine new instances, one of which caused severe melena. Arch Surg 1951;63:617-22.

3. Atkinson G, Gay BB, Naffis D. Intussusception of the appendix in children. Am factors. These abnormalities include fetal types of cecum, wide appendiceal lumen, thin mesoappendix, and active

J Radiol 1976;126:1164-8.

4. Bachman AL, Clement AR. Rontgen aspects of primary appendiceal intussusception. Radiology 1971;101:531-8.

5. Pardoll PM, Wilcoxen JK, Trudeau WL. Primary asymptomatic appendiceal intussusception. Gastrointest Endosc 1976;23:44.

6. Sonnino RE, Mohammed FLA. Intussusception of the appendix and endo- peristalsis within a normal appendix (7) It therefore seems that factors causing increased irritability (inflammation and endometriosis) or lesions which could act as 'leaders' in the inversion process (neoplasms, foreign bodies, en. dometriosis, etc) may cause inversion in an appendix anatomically capable of this maneuvre. The resultant vascular compromise could conceivably lead to mucosal ischemia, ulceration and secondary hemorrhage. In this case the hemorrhage was severe and potentially life threatening. The resultant hypovolemic shock and anemia were likely the major factors leading to fetal demise, although a fetal autopsy for confirmation was not obtained.

Inversion of the appendix may be asymptomatic or produce classic signs of intestinal intussusception (8). Massive hemorrhage is rare. The authors suggest that in the present case, decidualization of the ectopic endometrial stroma may have caused sig. nificant enlargement of the appendix and resultant inversion into the cecum.

metriosis. Henry Ford Hosp Med J 1986;34:61-4.

7. Forshall I. Intussusception of the vermiform appendix with a report of seven cases in children. Br J Surg 1953;40:305-12.

8. Fink VH, Santos AL, Goldberg SL. Intussusception of the appendix, case reports and review of the literature. Am J Gastroenterol 1964:42:431-41. 


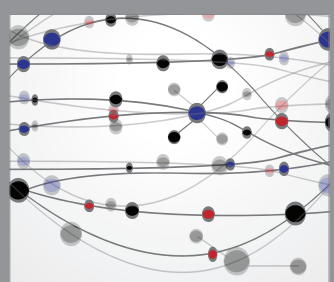

The Scientific World Journal
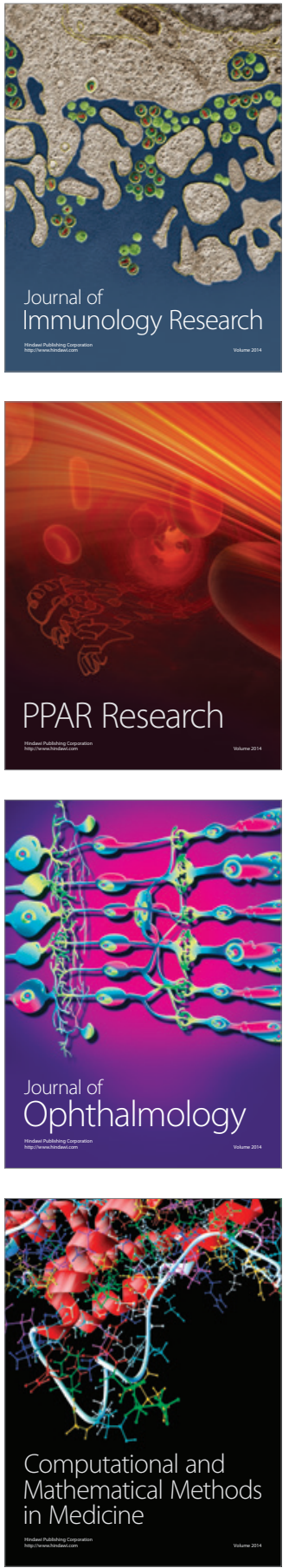

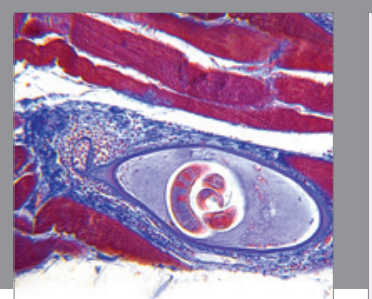

Gastroenterology Research and Practice

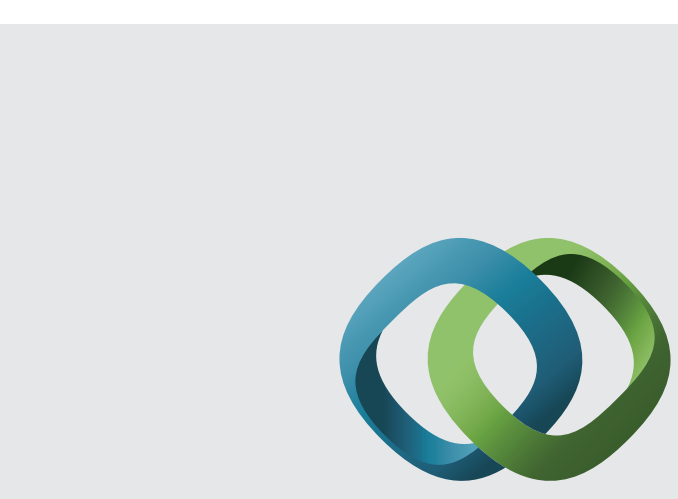

\section{Hindawi}

Submit your manuscripts at

http://www.hindawi.com
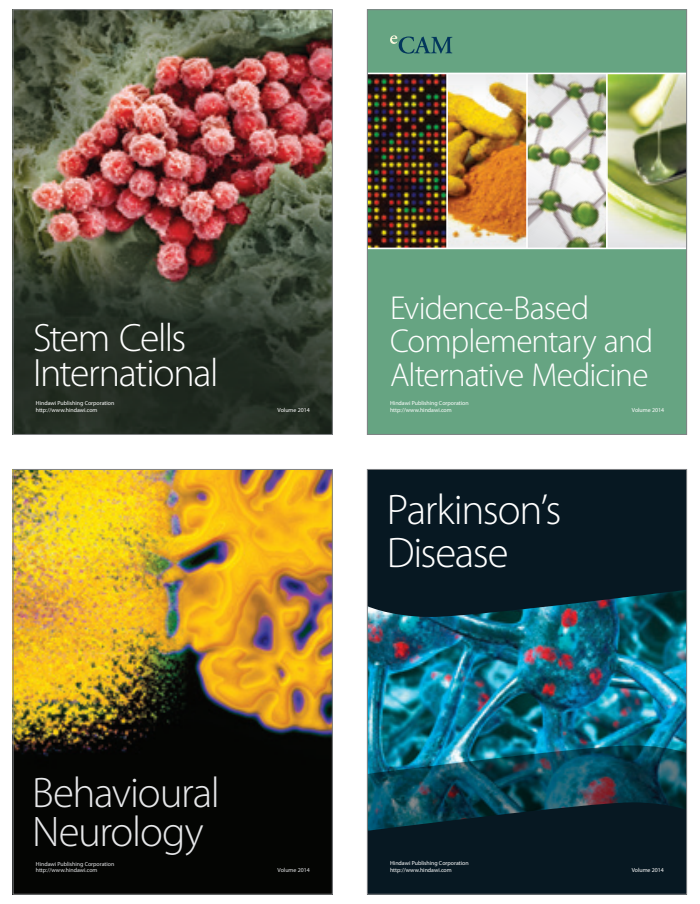
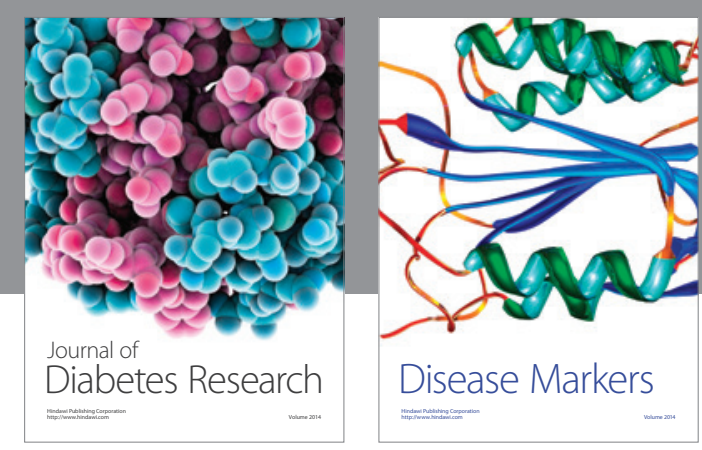

Disease Markers
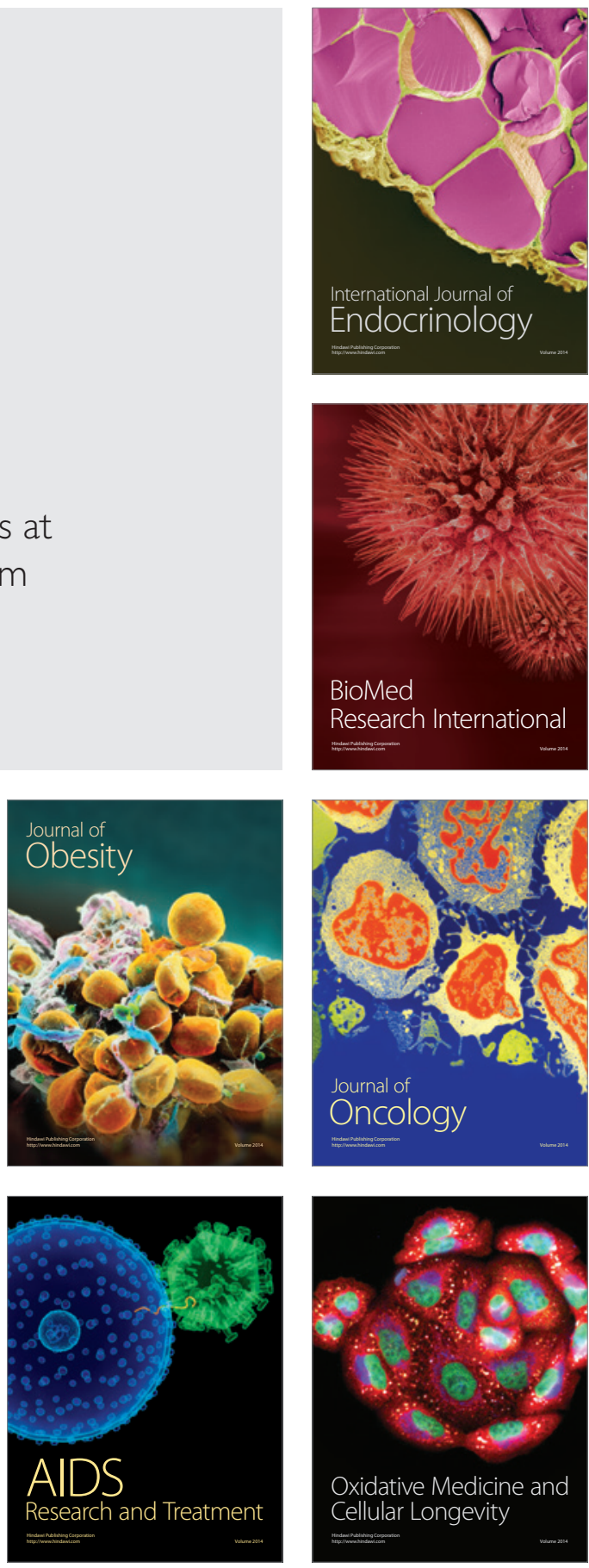